\section{Malerei, Bildhauerei, Musik und Dichtung}

\author{
S. Weiss
}

Vom 19. August 2000 bis 2. September 2000 fand die jährliche Kunstausstellung der gestaltenden Ärztinnen und Ärzte der Schweiz in den stilvollen Kellergewölben des Rathauses in Murten statt. Diese Ausstellung stand unter dem Thema "Mensch». Offenbar motivierte es viele von uns zum Gestalten, wurden doch über dreissig zum grossen Teil sehr eindrückliche Plastiken und viele Bilder mit der Darstellung des Menschen eingesandt. Die grosse Kreativität unserer Kolleginnen und Kollegen in vielerlei Techniken wie Steinhauerei, Aquarell, Öl, Kreide, Drucktechnik überraschte einmal mehr.

Eine ganze Reihe von schriftstellernden Kolleginnen und Kollegen sandten nach einem Aufruf in der "Distillerie" der Schweizerischen Ärztegesellschaft Gedichte ein, die von unserem komponierenden Arztkollegen, Jean-Luc Darbellay, teilweise vertont wurden. Vor der Vernissage kamen viele Zuhörer in der stimmungsvollen, intimen Französischen Kirche von Murten in den Genuss eines eindrücklichen Konzerts. Zunächst wurde ein Gedicht unseres Kollegen D. Künzler für Viola solo durch Noëlle Darbellay launisch dargebracht, gefolgt von 4 wunderbar lyrisch vertonten Liedern von Dr. Ulrich Ammann, Interlaken, aus einem Gedichtzyklus "Tessin», gesungen

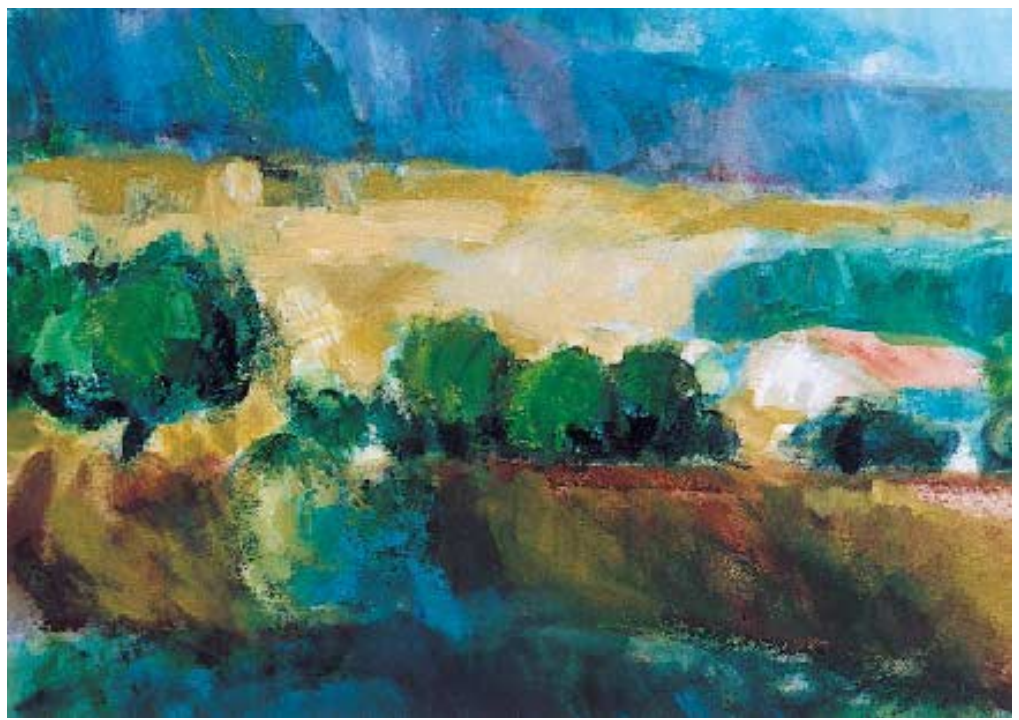

Jürg Zöbeli, Zürich: «Eichen am Lubéron (Provence)»

Korrespondenz:

Dr. med. Severin Weiss

Effingerstrasse $14 \mathrm{a}$

CH-3011 Bern

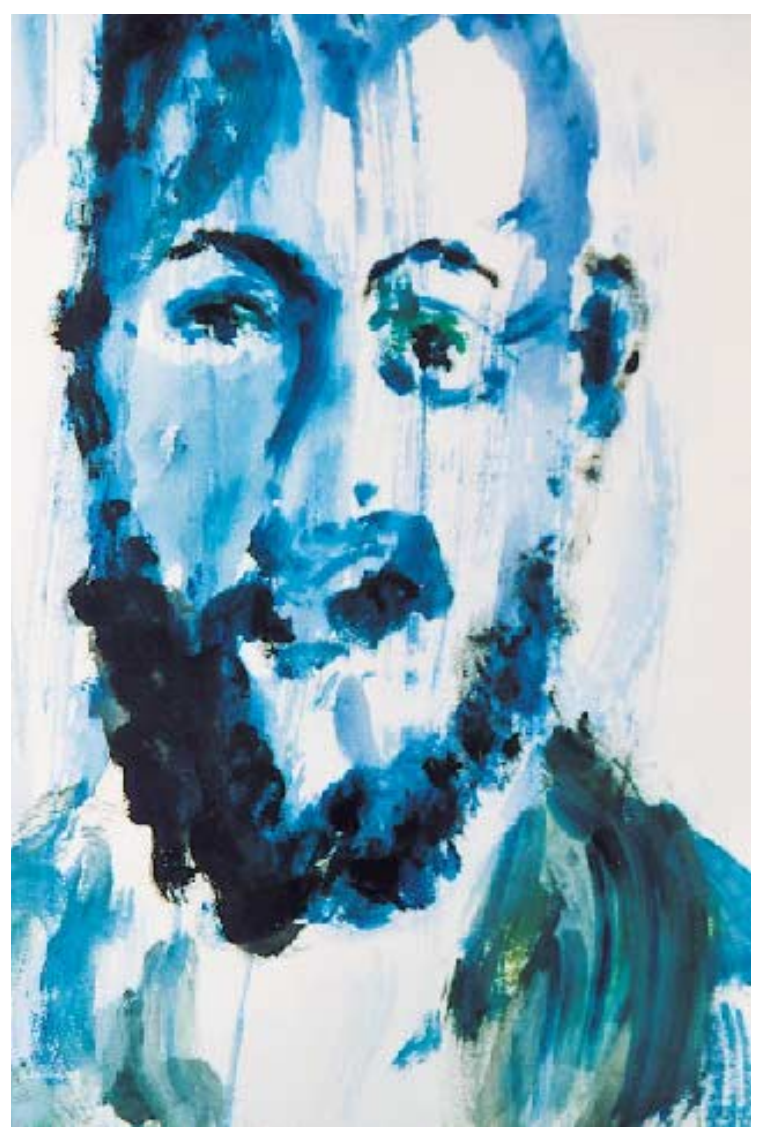

Severin Weiss, Bern: «Blaues Portrait»

vom Kollegen Heinz Fahrer, begleitet von Elisabeth und Jean-Luc Darbellay. Ein besonderer Genuss war dann das durch Darbellay vertonte Gedicht "Vestiges" der schriftstellernden Kollegin F. Verrey aus Biel, das die unglaubliche Vielseitigkeit des Fagotts zur Darstellung brachte. Das "memento mori» von D. Künzler für Bariton, 2 Violen und 2 Bassetthörner war tief ergreifend in seinen eindringlichen Quinten und der wunderbaren Melodie, die durch die seltene Instrumentenbesetzung unterstrichen wurde. Den rauschenden Abschluss bildete die "Evocation» für Violine, Cello und Harfe, in der Darbellay zeigte, wie moderne Musik mit dem klassischen Instrument Harfe zu einem herrlichen Genuss wird.

Auch dieses Jahr wurde nach lebhafter Diskussion beschlossen, ein Thema für die Kunstausstellung 2001 zu wählen. Es ist abstrakt und lautet «Freud und Leid, Schmerz, Polaritäten». Es wäre schön, wenn auch bis Ende des laufenden Jahres wieder möglichst viele Kolleginnen und Kollegen Gedichte einsenden könnten, die ich gerne unserem komponierenden Kollegen Jean-Luc Darbellay zur Vertonung und Uraufführung in der nächsten Ausstellung weitergeben würde.

Dank Sponsoring durch die Firmen Novartis, AstraZeneca, MSD und die Credit Suisse Private Banking konnte unser Jahresbeitrag, der im letzten Jahr erhöht werden musste, für das nächste Jahr wieder gesenkt werden. Im Namen unserer Vereinigung danke ich den Sponsoren herzlich. 


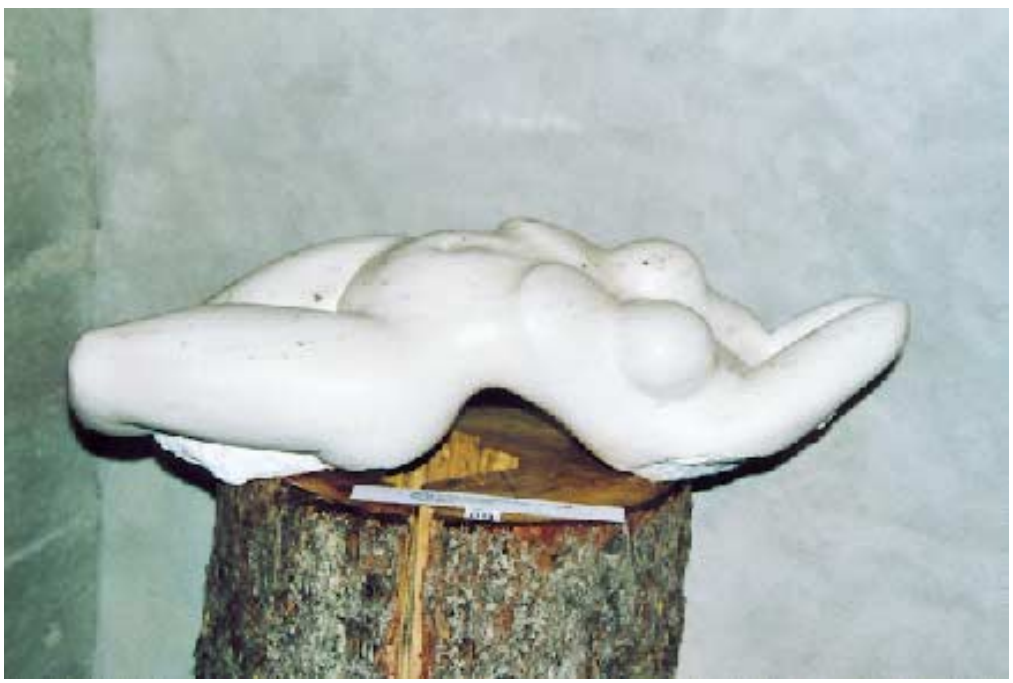

Jeorge M. Riesen, Zweisimmen: "femme tordue" freie Interpretation nach Rodin, Anhydrit poliert

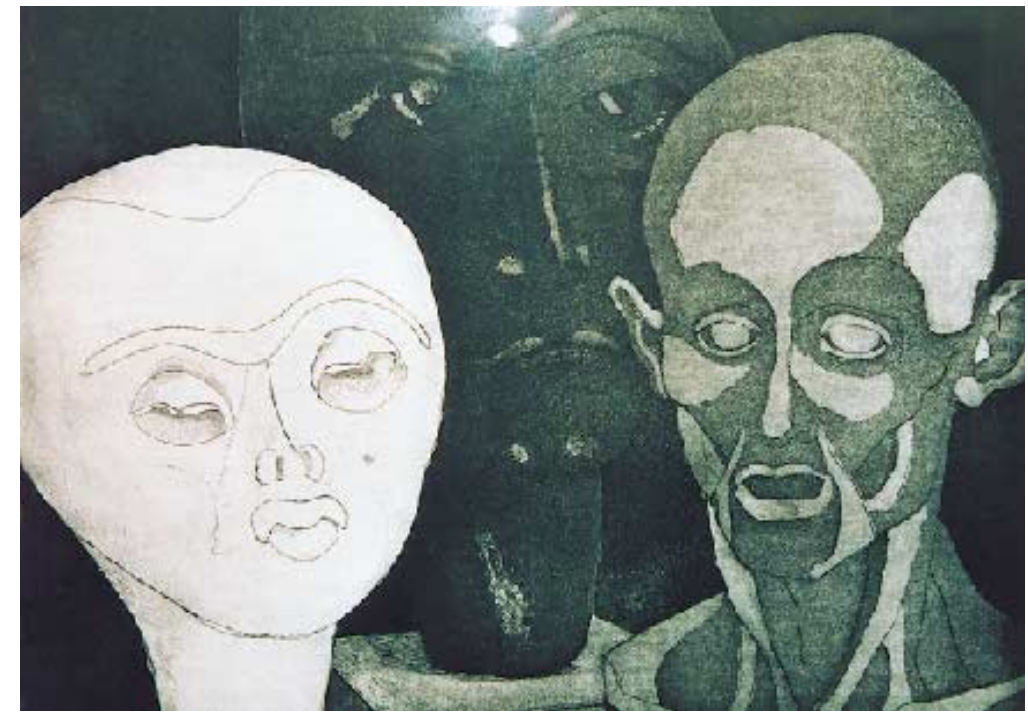

Theres Gensheimer, Basel: "Composition II" Radierung (Aquatinta)

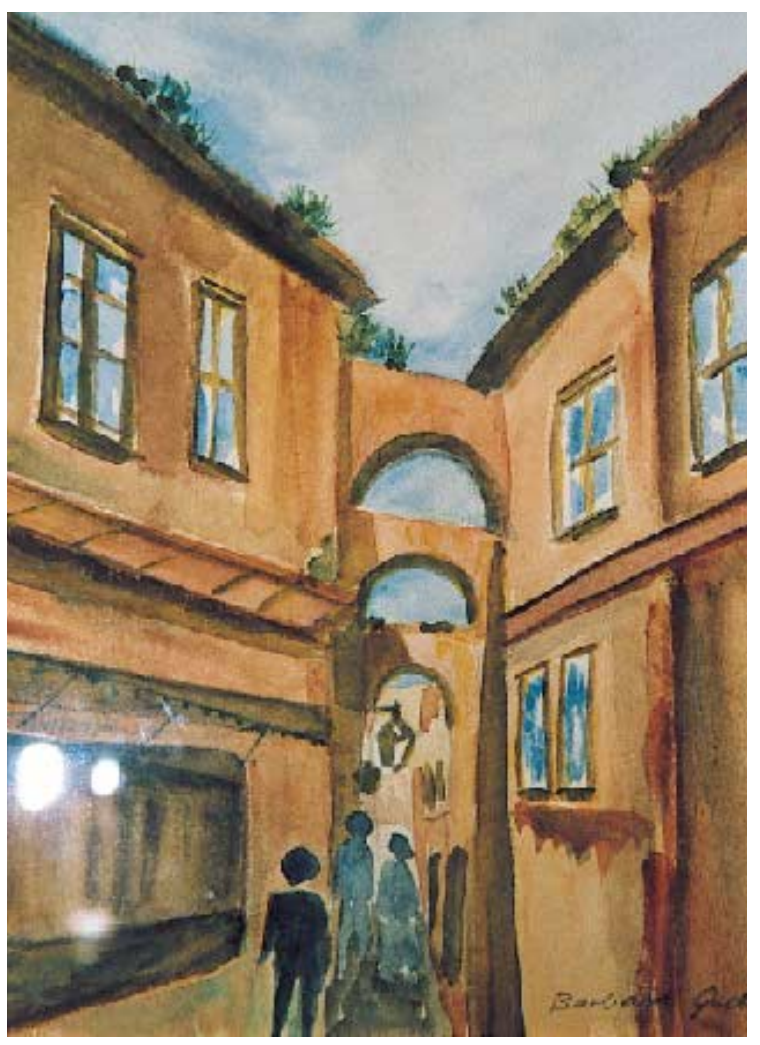

Barbara Gschwend, Gümligen: «Touristen»

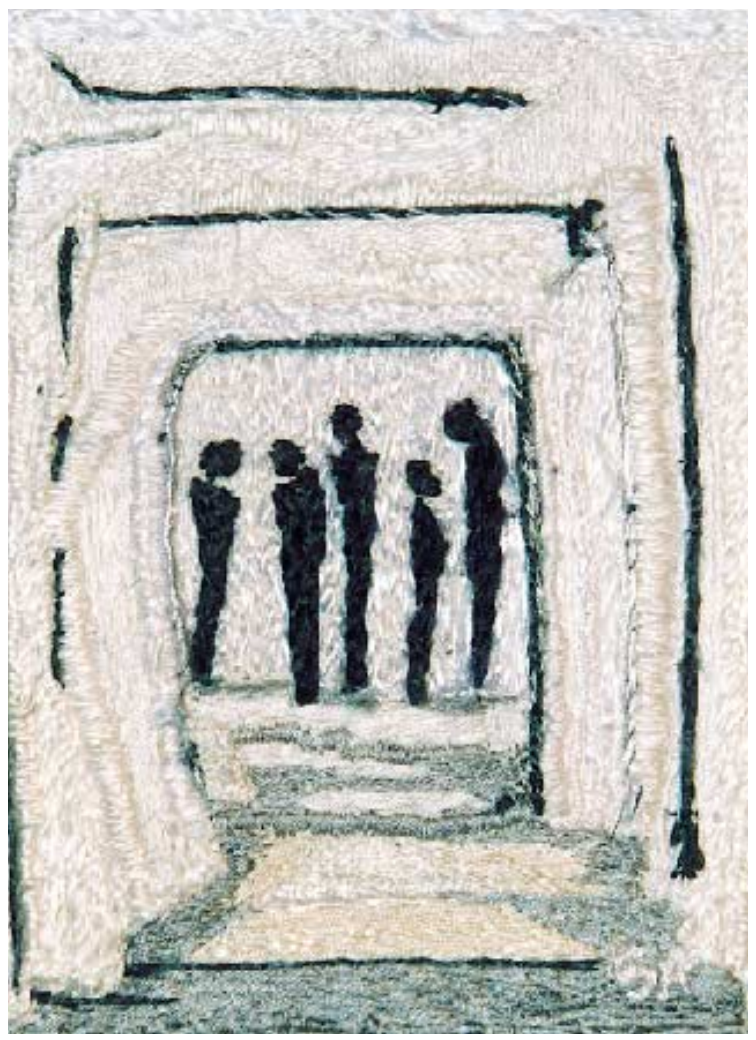

Susanne Reichen, Murten: «Solitude»

2 